\title{
Д.В. Попов
}

\section{ЭФФЕКТИВНОСТЬ ФИНАНСОВО-ЭКОНОМИЧЕСКОЙ ДЕЯТЕЛЬНОСТИ ВЫСШЕГО УЧЕБНОГО ЗАВЕДЕНИЯ}

\begin{abstract}
Статья является продолжением работ, посвященных исследованию изменений, которые происходят под влиянием глобализации выстего образования в национальных системах высшего образования. В статье даны определения выражениям «система финансирования высших учебных заведений национальной системы высшего образования», «финансово-экономическая деятельность высших учебных заведений», «эффективность финансово-экономической деятельности высших учебных заведений». Автор доказывает, что в настоящее время по отношению $\kappa$ высшим учебным заведениям следует использовать не выражение «финансово-хозяйственная деятельность», а выражение «финансово-экономическая деятельность». Проведен анализ взаимосвязей между системами финансирования высших учебных заведений национальных систем высшего образования, финансово-экономической деятельностью высших учебных заведений и тенденциями в национальных системах высшего образования в разрезе тенденций. На основании результатов проведенного анализа разработана схема совершенствования системы высшего образования, которая определяет эффективность финансово-экономической деятельности высшего учебного заведения как основу развития мировой системы высшего образования.

Ключевые слова: высшее образование, финансирование, финансово-экономическая деятельность, система финансирования, эффективность, тенденции, глобализация, конкуренция.
\end{abstract}

\section{Введение}

В предыдущих работах мы провели исследования по изучению влияния глобализации рынка высшего образования на национальные системы высшего образования и на основании полученных результатов выявили тенденции, свойственные большинству национальных систем высшего образования (далее - тенденции) [1].

В данной статье мы рассмотрим влияние тенденций на системы финансирования высших учебных заведений национальных систем высшего образования и финансово-экономическую деятельность высших учебных заведений.

Исследованию вопросов финансирования высших учебных заведений в условиях глобализации мирового рынка образования посвятили свои труды П. Алтбах [2], Ж. Винстон [3], Д. Джонстон [4], Д. Зиммерман [3], Д. Кинг [5], М. Кретович [6], С. Мишель [6].

Цель статьи - разработать схему совершенствования системы высшего образования на основе изменений в системах финансирования высших учебных заведений национальных систем высшего образования и в финансовоэкономической деятельности высших учебных заведений под влиянием тенденций в условиях глобализации мирового рынка высшего образования.. 


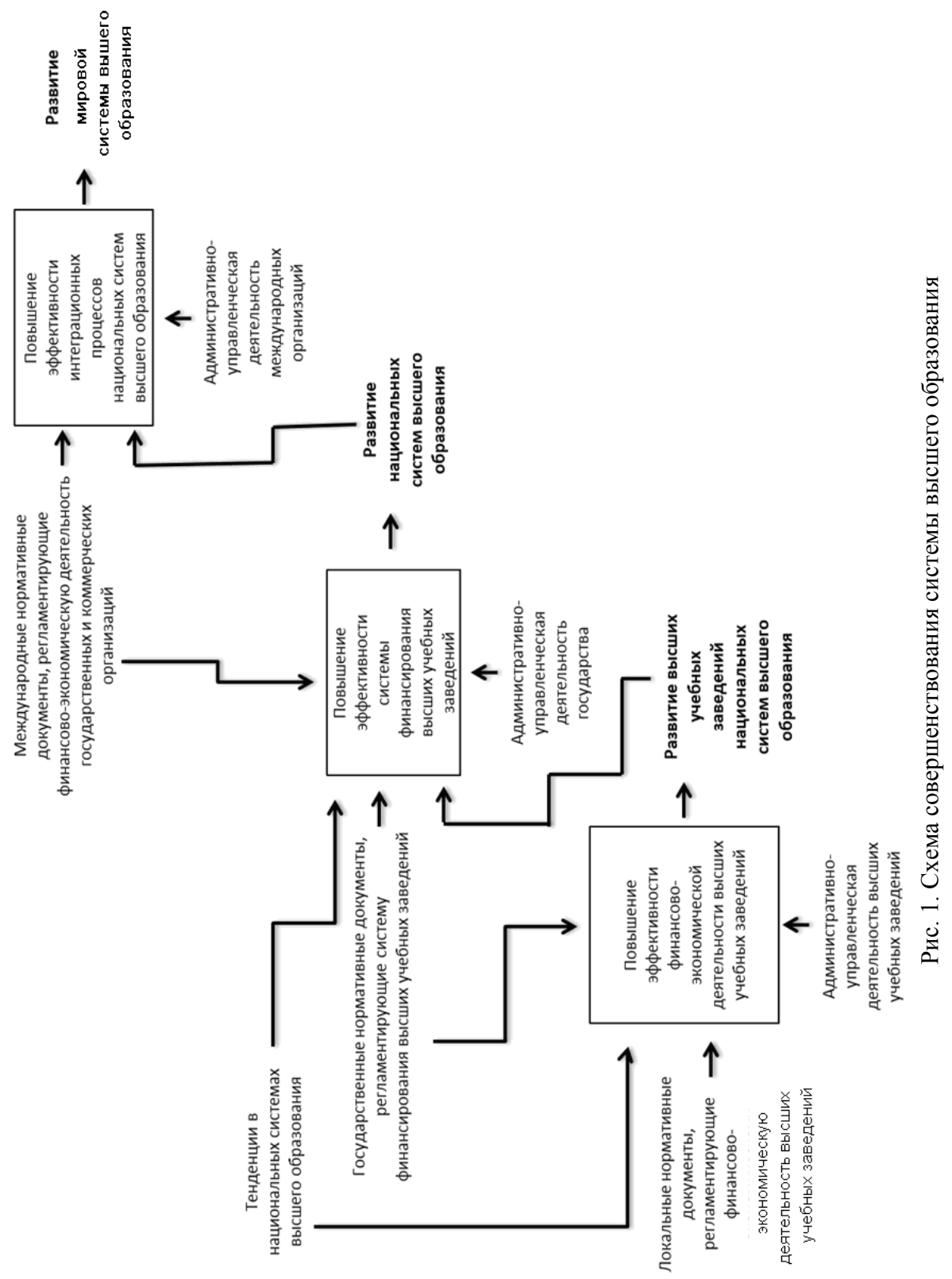




\section{Определения выражений}

Определим значения выражений, которые мы будем использовать.

Система финансирования высших учебных заведений национальной системы высшего образования - это совокупность финансовых отношений между субъектами национальной системы высшего образования, связанных с формированием, распределением, доведением и использованием денежных средств.

При изучении научной литературы мы обратили внимание на то, что выражение «финансово-экономическая деятельность» используется только для коммерческих учреждений. Для государственных учреждений используется выражение «финансово-хозяйственная деятельность».

На наш взгляд, это не правильно. Мы считаем, что в отношении казенных учреждений должно использоваться выражение «финансово-хозяйственная деятельность», а в отношении бюджетных и автономных учреждений следует использовать выражение «финансово-экономическая деятельность».

На примере высших учебных заведений как бюджетных учреждений поясним необходимость использования выражения «финансово-экономическая деятельность» по отношению к бюджетным и автономным государственным учреждениям.

После принятия Госдумой Российской Федерации в мае 2010 г. Федерального закона № 83-Ф3 «О внесении изменений в отдельные законодательные акты Российской Федерации в связи с совершенствованием правового положения государственных (муниципальных) учреждений» (далее - 83-ФЗ) [7] высшие учебные заведения получили право заниматься предпринимательством (приносящей доход деятельностью), т.е. хозяйственной деятельностью, связанной с производством и реализацией продукции, выполнением работ, оказанием услуг или же продажей товаров, необходимых потребителю, с целью получения прибыли.

Предпринимательская деятельность имеет регулярных характер и отличается, во-первых, свободой в выборе направлений и методов деятельности, самостоятельностью в принятии решений (разумеется, в рамках закона и направленных норм); во-вторых, ответственностью за принимаемые решения и их использование. В-третьих, этот вид деятельности не исключает риска и убытков. Наконец, предпринимательство четко ориентировано на получение прибыли, чем в условиях развитой конкуренции достигается и удовлетворение общественных потребностей. Это важнейшая предпосылка и причина заинтересованности в результатах своей деятельности.

Кроме этого, государственное финансирование до высших учебных заведений после принятия 83-Ф3, доводится на конкурсной основе в виде государственных субсидий на выполнение государственных заданий.

Поэтому для принятия тех или иных решений при управлении высшими учебными заведениями нужно иметь представление не только о ходе выполнения плана (задания), результатах хозяйственной деятельности, но и о тенденциях и характере происходящих изменений в экономике как высшего учебного заведения, так и отрасли, региона, государства. В связи с этим не- 
маловажным становится проведение различных видов экономического анализа, с помощью которого достигается осмысление, понимание информации.

Следует отметить, что «экономика» в переводе с греческого означает «законы хозяйства», т.е. финансово-экономическая деятельность на микроуровне - это не что иное, как финансово-хозяйственная деятельность.

Чтобы выжить в современных условиях, руководству высшего учебного заведения необходимо, прежде всего, уметь реально оценивать финансовое состояние как своего учреждения, так и существующих конкурентов.

Основным инструментом для оценки финансового состояния высших учебных заведений является финансовый анализ, который характеризует итоги финансово-экономической деятельности.

Для принятия того или иного решения руководству необходимо проанализировать обеспеченность высшего учебного заведения финансовыми ресурсами, целесообразность и эффективность их размещения и использования, платежеспособность учреждения и его финансовые взаимоотношения с контрагентами.

Анализ и оценка финансовых показателей необходимы для эффективного управления высшими учебными заведениями. Основываясь на результатах финансового анализа, руководство высших учебных заведений может осуществлять планирование, контроль, улучшать и совершенствовать направления своей деятельности.

Очевидно, что от эффективности управления финансовыми ресурсами и высшим учебным заведением целиком и полностью зависит результат деятельности высшего учебного заведения в целом. Если дела в высшем учебном заведении идут самотеком, а стиль управления в новых рыночных условиях не меняется, то ни о каком развитии не может быть и речи. Такие высшие учебные заведения ежедневно борются за выживание, и эта борьба становится непрерывной.

Анализ финансово-экономической деятельности является одним из наиболее действенных методов управления, важным элементом обоснования руководящих решений. Он основан на системном подходе, комплексном учете разнообразных факторов, качественном подборе достоверной информации и является существенной функцией управления.

Таким образом, финансово-экономическую деятельность высших учебных заведений мы определим как деятельность высших учебных заведений по экономическому анализу тенденций и характера происходящих изменений в экономике на микро- и макроуровнях, по оценке и анализу финансовой деятельности учреждения и по принятию с учетом результатов финансово-экономического анализа обоснованных решений по развитию учреждения высшего образования на кратко -, средне - и долгосрочные периоды времени.

Для того чтобы дать определение выражению «эффективность финансово-экономической деятельности высших учебных заведений», определим значение, в котором употребляется термин «эффективность» в данном выражении.

В настоящее время достаточно часто употребляется термин «эффективность». При этом не менее часто возникает вопрос, связанный со значением 
данного термина. В зависимости от области применения этому термину присваиваются разные значения [8].

Первые упоминания термина «эффективность» относят ко второй половине XVII в. в работах Уильяма Петти в значении результативности. Используется термин для оценки действий правительства как субъекта управления на оживление экономической жизни.

В XVIII в. в том же значении термин «эффективность» употребляет в своих работах Франсуа Кенэ. При этом Уильям Петти и Франсуа Кенэ термин «эффективность» как самостоятельное экономическое понятие не разрабатывали.

Как самостоятельная экономическая категория термин «эффективность» рассматривается с начала XIX в. в работах Давида Рикардо.

Давид Рикардо определял «эффективность» как отношение результата к определенному виду затрат и использовал это определение для оценки эффективности капитала.

В связи с развитием науки и крупными научными открытиями термин «эффективность» постепенно, к концу XIX в., теряет своё чисто экономическое значение. Его начинают применять в других сферах деятельности.

Г. Эмерсон считал эффективность основной задачей управления. В 1900 г. выходит его книга «Эффективность как основание для управления и оплаты труда», а в 1912 г. «Двенадцать принципов эффективности».

T. Котарбиньским во второй половине 70-х гг. XX в. оформляются теоретические разработки в праксиологии - области социологических исследований, которая изучает методику рассмотрения различных действий или совокупности действий с точки зрения установления их эффективности. В целом термин «эффективность» у Котарбиньского отличается многозначностью употребления, что обусловливает в какой-то мере теоретическую неопределенность этого понятия в рамках праксиологии.

Использование термина за пределами экономических границ привело к необходимости введения новой критериальной основы, при определении которой до сих пор не наблюдается какого-либо единства. Представителей, формулирующих критериальные основы, условно можно разделить на две группы, которые:

-эффективность определяют только на основе экономических критериев;

-считают, что эффективность, помимо экономических, учитывает социальные, психологические, территориальные, политические и другие критерии.

Так, например, П. Роби и К. Сейлз предложили следующий список критериев оценки эффективности управления, ориентируясь главным образом на коммерческие организации: качество управления; качество продукции и услуг; способность к нововведениям; объем долгосрочных инвестиций; финансовое положение; способность к привлечению, развитию высококачественных человеческих ресурсов; ответственность перед обществом и окружающей средой; широкое использование активов компании.

Прежде чем рассматривать современные определения термина «эффективность», определим термин «результативность». 
Т.В. Файберг определяет эффективность и результативность следующим образом [9]:

эффективность - соотношение результатов и затрат на эти цели;

результативность - польза или выгода от результатов работы.

Аналогично через соотношение результата и затрат дают определение понятию эффективности следующие авторы:

Е.Е. Румянцева [10]: эффективность - степень соизмерения результатов с затратами; система показателей, характеризующих уровень использования производственных мощностей системы;

Л.П. Кураков, В.Л. Кураков [11]: эффективность деятельности - результативность экономической деятельности, определяемая как отношение полученного экономического эффекта и затрат, обусловивших получение этого эффекта;

А.К. Осипов и др. [12]: эффективность - совокупная результативность работы, действия, системы мероприятий, являющихся следствием определенных материальных усилий.

Изучая научные работы, посвященные исследованию эффективности деятельности бюджетных учреждениях, мы сталкиваемся с иными определениями понятия эффективности:

М.П. Придачук [13]: эффективность - степень достижения поставленных целей;

И.И. Мазур [14]: эффективность использования бюджетных средств определяется не столько традиционными объективными показателями действенности решений по типу: «затраты-выпуск» или «затраты-результат», сколько по соотношению результатов и ресурсов, использованных для достижения стратегических целей политической системы и реализации общих государственных интересов.

Таким образом, понятие «эффективность» для бюджетных учреждений рассматривается через призму достижения стратегических целей и интересов учреждения и его учредителя.

Повышение эффективности системы управления высших учебных заведений исследуют Т.В. Ивашкевич, А.Г. Кириллов, Ю.И. Щербаков и др. В ходе исследования определяют эффективность системы управления высших учебных заведений. Так, например, Т.В. Ивашкевич [15] дает следующее определение: эффективность управления высшим учебным заведением - основной показатель совершенства управления, определяемый посредством сопоставления совокупности показателей эффективности аппарата управления (внутренней эффективности) и эффективности его влияния на объекты управления, характеризующиеся конечными результатами их деятельности (внешней эффективности).

Таким образом, термин «эффективность» в выражении «эффективность финансово-экономической деятельности высших учебных заведений» определяется особенностями организации и деятельности высших учебных заведений, обусловленных сочетанием государственных интересов, продиктованных учредителем и иными исполнительными органами власти (федеральными, региональными, местными), и коммерческих интересов, продиктованных собственной финансово-экономической деятельностью. 
Эффективность финансово-экономической деятельности высших учебных заведений - основной показатель совершенства управления, определяемый сопоставлением совокупности показателей эффективности управления финансово-экономической деятельностью высших учебных заведений аппаратом управления и эффективности его влияния на объекты управления, характеризующиеся конечными результатами их деятельности.

\section{Взаимосвязь систем финансирования высших учебных заведений и тенденций в национальных системах высшего образования}

Далее рассмотрим, как взаимосвязаны между собой системы финансирования высших учебных заведений национальных систем высшего образования, финансово-экономическая деятельность высших учебных заведений и тенденции в национальных системах высшего образования в разрезе тенденций.

\section{1.Приватизащчия высшего образования}

Преследуя только коммерческие цели, частные высшие учебные заведения нередко не учитывают иных, не менее важных целей деятельности, которые иногда противоречат коммерческим целям и, следовательно, требуют различных оперативных подходов для их достижения. Так, например, одним из основных направлений деятельности высших учебных заведения является научно-исследовательская деятельность, которая ориентирована на получение новых знаний, связанных с совершенствованием практической деятельности. Поиск новых знаний влечет за собой непрерывное экспериментирование, которое не всегда имеет результат, а если даже и имеет, то не всегда покрывает этим результатом затраты, понесенные высшим учебным заведением на его получение.

Для частных высших учебных заведений это недопустимо, так как противоречит основной цели их создания.

Тем не менее правительства многих стран продолжают вести политику приватизации учреждений высшего образования, что приведет к росту числа учащихся, посещающих частный сектор высшего образования, и увеличению роли рыночных сил в системе высшего образования.

\section{2.Институцчиональная диверсификациия}

Через систему финансирования высших учебных заведений государства оказывают влияние на институциональное разнообразие, стимулируя развитие отдельных направлений. Например, если государство направляет значительные финансовые ресурсы на научно-исследовательскую деятельность, то научно-исследовательские университеты в этом государстве будут развиваться.

Таким образом, обязанностью государства является обеспечение с помощью системы финансирования высших учебных заведений институцииональной диверсификации национальной системы высшего образования, необходимой для развития общества. 
3.Увеличение государственного участия в финансировании высших учебных заведений

Рост количества студентов и развитие частного сектора высшего образования способствовали увеличению количества мест платного обучения по программам высшего образования в национальных системах образования.

Для того чтобы обеспечить доступность к получению платного обучения по программам высшего образования всем студентам, в том числе и студентам из низших социально-экономических слоев общества, государствам необходимо выстроить систему финансирования высшего образования, ориентированную на персональную государственную поддержку нуждающихся студентов в виде полного или частичного возмещения платы за их обучение.

Ответственность за построение такой системы финансирования полностью лежит на соответствующих государственных органах, в обязанности которых также входит постоянный мониторинг влияния механизмов государственного финансирования на высшее образование.

4. Диверсификация источников финансирования высших учебных заведений

Сокращение финансирования высших учебных заведений из государственных источников, без предварительного создания условий и стимулов для развития альтернативных источников финансирования, может поставить под угрозу существование учреждения. Но даже если условия и стимулы для развития альтернативных источников финансирования государством будут созданы, при уменьшении государственного финансирования в большинстве случаев в высших учебных заведениях произойдет смена приоритетов. Это может привести к ухудшению качества предоставляемых услуг, оттоку высококвалифицированных преподавателей, научных работников и специалистов, к запущенному состоянию имущественного комплекса и снижению качества обучения.

Таким образом, в процессе реализации политики диверсификации источников финансирования государству следует постоянно осуществлять мониторинг деятельности высших учебных заведений и корректировать свою деятельность с учетом полученных результатов.

\section{5. Разнообразие студенческого сообщества}

Используя различные механизмы финансирования, государство может поддерживать (или не поддерживать) разнообразие студентов в высших учебных заведениях.

\section{6. Увеличение числа платных студентов}

Как уже было сказано ранее, рост количества студентов и развитие частного сектора высшего образования способствовали увеличению количества мест платного обучения по программам высшего образования в национальных системах образования. Непреднамеренным последствием роста числа платных студентов является то, что плохо обеспеченным студентам, у которых отсутствует возможность взять кредит, будет сложнее получить высшее образование. 
Таким образом, государству необходимо осуществлять постоянный мониторинг влияния системы финансирования высших учебных заведений на различные слои населения.

\section{7. Увеличение отчетности и ужесточение контроля}

Рост отчетности в высших учебных заведениях стимулировал увеличение расходов:

-на содержание существующего и дополнительного персонала;

-повышение квалификации персонала;

-разработку новых или доработку существующих информационных систем.

Высшие учебные заведения вынуждены нести эти расходы, особенно в тех случаях, когда объем их государственного финансирования полностью зависит от отчетности.

\section{8.Институцииональный рейтинг}

Институциональный рейтинг, по сути, является инструментом, который стимулирует государства осуществлять усиленное финансирование более развитых высших учебных заведений.

Очевидно, что чем выше учреждение в рейтинге, тем больше это учреждение тратит денежных средств на подготовку одного студента, соответственно, в это учреждение должно поступать больше государственных средств.

9. Повышение эффективности финансирования высших учебных заведений

В сознании политиков эффективность финансирования ассоциируется с повышением качества соразмерно потраченным денежным средствам.

В связи с этим как приоритетные критерии оценки эффективности использования государственного финансирования высшими учебными заведениями в XXI в. большинство стран определило качество финансового менеджмента с ориентацией на конечный результат.

\section{0. Анализ стоимости услуг и оптимизация затрат}

Столкнувшись с нехваткой финансовых ресурсов, большинство стран пересмотрело систему финансирования высших учебных заведений в направлении детализации финансируемых услуг, анализа их стоимости и оптимизации затрат по основным видам деятельности.

В свою очередь, большинство высших учебных заведений стали более сознательными экономически и разработали и продемонстрировали свои стратегии по сокращению затрат.

Таким образом, тенденции в национальных системах высшего образования, с одной стороны, оказывают влияние на системы финансирования высших учебных заведений, с другой - через системы финансирования высших учебных заведений государства стимулируют (или дестимулируют) развитие тенденций в национальных системах высшего образования. 


\section{Результаты исследования}

При осуществлении финансово-экономической деятельности высшие учебные заведения должны учитывать тенденции. Чем точнее проведен экономический анализ и исследованы и учтены при осуществлении финансовоэкономической деятельности тенденции в национальных системах высшего образования, тем выше уровень эффективности этой финансовоэкономической деятельности.

Основой развития национальных систем высшего образования в ближайшем будущем станет усовершенствованная, с учетом влияния обозначенных тенденций, система финансирования высших учебных заведений (макроуровень), а основой развития высших учебных заведений национальных систем высшего образования в ближайшем будущем станет усовершенствованная, с учетом влияния обозначенных тенденций, финансово-экономическая деятельность высших учебных заведений (микроуровень).

При этом развитие мировой системы высшего образования определяется повышением эффективности интеграционных процессов национальных систем высшего образования и напрямую зависит от уровня развития национальных систем высшего образования, а развитие национальных систем высшего образования напрямую зависит от развития высших учебных заведений.

Таким образом, процесс совершенствования системы высшего образования в схематическом виде, разработанном в соответствии с методологией функционального моделирования IDEF0, будет иметь, представленный вид на рис. 1.

\section{Выводы}

Разработанная схема совершенствования системы высшего образования наглядно демонстрирует зависимость мировой системы высшего образования, национальных систем высшего образования и учебных заведений высшего образования от эффективности финансово-экономической деятельности высших учебных заведений.

С целью контроля и мониторинга эффективности финансовоэкономической деятельности высших учебных заведений в последующем автором будет разработан методический подход к оценке эффективности финансово-экономической деятельности высших учебных заведений.

\section{Литература}

1. Попов, Д.В. Влияние глобализации на национальные системы высшего образования // Успехи современной науки. 2016. № 10 (4). С. 84-89.

2. Altbach $P$. The funding of higher education: International perspectives. New York, NY: Garland Publishing. 1993.

3. Winston G.C., Zimmerman D. Where is aggressive price competition taking higher education? // The Magazine of Higher Learning. 2000. № 32(4). P. 10-19.

4. Johnstone D.B. The costs of higher education: Worldwide issues and trends for the 1990s // The funding of higher education: International perspectives. New York: Garland Publishing, 1993. P. 3-24. 
5. King J.E. Financing a college education: How it works, how it's changing // Phoenix, AZ: The American Council on Education and The Oryx Press, 1999.

6. Michael S.O., Kretovics M.A. Financing higher education in a global market. New York: Algora Publishing, 2005. 344 p.

7. Федеральный закон от 8 мая 2010 г. N 83-Ф3 «О внесении изменений в отдельные законодательные акты Российской Федерации в связи с совершенствованием правового положения государственных (муниципальных) учреждений» // СПС «КонсультантПлюс: Версия Проф» [Электронный ресурс] / Компания «Консультант Плюс». (дата обращения: 29.01.2017).

8. Попов Д.В. Исследование понятия эффективности. Определение понятия эффективности финансирования бюджетных учреждений // Экономика и социум. 2016. № 2 (21). С. 790-795.

9. Файберг Т.В. Оценка результативности деятельности бюджетных учреждений // Изв. Иркут. гос. экон. академии. 2006. № 2 (47). С. 23-25.

10.Румянцева Е.Е. Новая экономическая энциклопедия. М.: ИНФРА, 2005. 723 с.

11.Кураков Л.П., Кураков В.Л. Толковый словарь экономических и юридических терминов. М.: Московский психолого-социальный институт. 2002. 747 с.

12. Методика оценки эффективности использования государственных средств (монография). Ижевск: Изд-во ИжГТУ, 2006.

13.Придачук М.П. Методы экономического анализа эффективности затрат на получение бюджетных услуг // Финансы. 2006. № 5. С. 27-30. 2003.

14. Мазур И.И., Шапиро В.Д., Ольдерогzе Н.Г. Эффективный менеджмент. М.: Высшая шк.,

15.Ивашкевич Т.В. Эффективность управления вузом // Экономика образования № 1. 2010. C. $60-63$.

Popov D.V., postgraduate student, assistant of the Department "Financial markets and financial institutions" Novosibirsk State University of Economics and Management (Novosibirsk, Russia). E-mail: dmit-popov@yandex.ru

HIGHER EDUCATION INSTITUTE EFFECTIVENESS OF FINANCIAL AND ECONOMIC ACTIVITIES

Keywords: higher education, financing, financial and economic activities, financing system, efficiency, trends, globalization, competition.

This article is the continuation of works devoted to the study of changes that occur under the influence of the higher education in national systems of higher education globalization. The article gives the definition of following expressions: "The financing system of higher education institutions of national education system", "Financial and economic activities of higher education institutions", "The effectiveness of the financial and economic activities of higher education institutions". Author proves that, at present, in relation to higher education institutions should not be used expression "Financial and operational activities", but the expression "financial and economic activities". Was held the analysis of relationships between systems of financing higher education institutions of national higher education systems, financial and economic activities of higher educational institutions and trends in national systems of higher education according to the trends. Based on the results of the analysis, a scheme for improving the higher education system was designed. The scheme allows to determine the efficiency of financial and higher education institutions economic activities as basis for development of the world higher education system.

\section{References}

1. Popov D. V., Vliyaniye globalizatsii na natsionalnyye sistemy vysshego obrazovaniya / D.V. Popov, Uspekhi sovremennoy nauki. 2016. 10 (4), pp. 84-89.

2. Altbach, P. The funding of higher education: International perspectives / P. Altbach // New York, NY: Garland Publishing. 1993.

3. Winston G. C., Zimmerman D. Where is aggressive price competition taking higher education? // The Magazine of Higher Learning. 2000. № 32(4), pp. 10-19.

4. Johnstone, D. B., The costs of higher education: Worldwide issues and trends for the 1990s. / D. B. Johnstone // The funding of higher education: International perspectives. New York, NY: Garland Publishing. 1993, pp. 3-24. 
5. King, J. E. Financing a college education: How it works, how it's changing. / J.E. King // Phoenix, AZ: The American Council on Education and The Oryx Press. 1999.

6. Michael S. O., Kretovics M. A. Financing higher education in a global market. New York: Algora Publishing, 2005. Vol., 344 p.

7. Federal Law of May 8, 2010 N 83-FL "On amendments to certain legislative acts of the Russian Federation in connection with the improvement of the legal status of state (municipal) institutions" // "Consultant Plus: Version Prof": [electronic resource] / The company "Consultant Plus". Renewal date: $29 / 01 / 2017$

8. Popov D.V., Issledovaniye ponyatiya effektivnosti. Opredeleniye ponyatiya effektivnosti finansirovaniya byudzhetnykh uchrezhdeniy / D.V. Popov // Ekonomika i sotsium. 2016. № 2 (21), pp. 790-795

9. Fayberg T.V., Otsenka rezul'tativnosti deyatel'nosti byudzhetnykh uchrezhdeniy // Irkutsk: Nauchnyy zhurnal «Izvestiya Irkutskoy gosudarstvennoy ekonomicheskoy akademii» №2 (47). 2006, pp. 23-25 pp. 810

10. Rumyantseva, E.E., Novaya ekonomicheskaya entsiklopediya // Moskva: INFRA. 2005,

11. Kurakov L.P., Kurakov V.L., Tolkovyy slovar ekonomicheskikh i yuridicheskikh terminov // Moskva: Moscow psycho - social institution. 2002, 748 p.

12. Osipov A.K., Anikin V.N., Kotlyachkov O.V., Konyarova E.K., Ilina T.A., Metodika otsenki effektivnosti ispolzovaniya gosudarstvennykh sredstv (monografiya)// Izhevsk: Publishing house IzhGTU. 2006, p. 8

13. Pridachuk, M.P., Metody ekonomicheskogo analiza effektivnosti zatrat na polucheniye byudzhetnykh uslug // Finansy. 2006. № 5, p. 27

14. Mazur I.I., Shapiro V.D., Olderogge N.G., Effektivnyy menedzhment // Moskva: High school. 2003. $555 \mathrm{p}$.

15. Ivashkevich T.V., Effektivnost upravleniya vuzom // Moskva: Ekonomika obrazovaniya № 1. 2010, pp. 60-63

Popov D.V. Effektivnost finansovo-ekonomicheskoy deyatelnosti vyisshego uchebnogo zavedeniya [Higher education institute effectiveness of financial and economic activities]. Vestnik Tomskogo gosudarstvennogo universiteta. Ekonomika - Tomsk State University Journal of Economics, 2017, no 37 , pp. 169-180. 